\title{
Application of in silico bulked segregant analysis for rapid development of markers linked to Bean common mosaic virus resistance in common bean
}

\author{
Marco H Bello ${ }^{1}$, Samira M Moghaddam², Mark Massoudi ${ }^{3}$, Phillip E McClean², Perry B Cregan ${ }^{4}$ and Phillip N Miklas ${ }^{* *}$
}

\begin{abstract}
Background: Common bean was one of the first crops that benefited from the development and utilization of molecular marker-assisted selection (MAS) for major disease resistance genes. Efficiency of MAS for breeding common bean is still hampered, however, due to the dominance, linkage phase, and loose linkage of previously developed markers. Here we applied in silico bulked segregant analysis (BSA) to the BeanCAP diversity panel, composed of over 500 lines and genotyped with the BARCBEAN_3 6K SNP BeadChip, to develop codominant and tightly linked markers to the / gene controlling resistance to Bean common mosaic virus (BCMV).

Results: We physically mapped the genomic region underlying the / gene. This locus, in the distal arm of chromosome Pv02, contains seven putative NBS-LRR-type disease resistance genes. Two contrasting bulks, containing BCMV host differentials and ten BeanCAP lines with known disease reaction to BCMV, were subjected to in silico BSA for targeting the I gene and flanking sequences. Two distinct haplotypes, containing a cluster of six single nucleotide polymorphisms (SNP), were associated with resistance or susceptibility to BCMV. One-hundred and twenty-two lines, including 115 of the BeanCAP panel, were screened for BCMV resistance in the greenhouse, and all of the resistant or susceptible plants displayed distinct SNP haplotypes as those found in the two bulks. The resistant/susceptible haplotypes were validated in 98 recombinant inbred lines segregating for BCMV resistance. The closest SNP ( 25-32 kb) to the distal NBS-LRR gene model for the / gene locus was targeted for conversion to codominant KASP (Kompetitive Allele Specific PCR) and CAPS (Cleaved Amplified Polymorphic Sequence) markers. Both marker systems accurately predicted the disease reaction to BCMV conferred by the / gene in all screened lines of this study.

Conclusions: We demonstrated the utility of the in silico BSA approach using genetically diverse germplasm, genotyped with a high-density SNP chip array, to discover SNP variation at a specific targeted genomic region. In common bean, many disease resistance genes are mapped and their physical genomic position can now be determined, thus the application of this approach will facilitate further development of codominant and tightly linked markers for use in MAS.
\end{abstract}

Keywords: Marker-assisted selection, Molecular breeding, KASP, CAPS, Disease resistance

\section{Background}

Traditional plant breeding relies on the discovery, phenotypic selection, and introgression of desirable traits to develop superior cultivars (e.g., with improved agronomic traits, pest and disease resistance, abiotic stress tolerance). This process usually takes 7-10 years

\footnotetext{
* Correspondence: phil.miklas@ars.usda.gov

${ }^{1}$ Vegetable and Forage Crops Research Unit, USDA, Agricultural Research

Service, Prosser, WA 99350, USA

Full list of author information is available at the end of the article
}

and significant economic resources [1]. However, the application of marker-assisted selection (MAS), for the detection of genes or genomic regions underlying a trait of interest, can increase the genetic gain over phenotypic selection in breeding programs by reducing time and costs $[2,3]$.

In the past three decades, molecular markers have been employed in common bean (Phaseolus vulgaris L.) for studies of genetic diversity, germplasm characterization, genetic mapping of major genes or quantitative trait loci 
(QTL) controlling agronomic traits or tolerance to abiotic stresses, and tagging and MAS of disease resistance genes [4-6]. Early discovery of molecular markers [e.g., restriction fragment length polymorphism (RFLP), random amplified polymorphic DNA (RAPD) sequence, and amplified length polymorphism (AFLP)] often focused on variation between genetically distant materials from different market classes belonging to the Middle American and Andean gene pools [4]. In the past, genetic maps were mostly generated from wide crosses and were not sufficiently dense with markers. In addition, markers linked to a given trait were often times not found in other unrelated populations, restricting their potential use for MAS [5] to certain populations or gene pools in common bean.

As an alternative to bi-parental linkage mapping for the identification of markers tightly linked to monogenic and quantitative disease resistance loci, bean geneticists developed molecular tagging methods utilizing several types of segregating populations, including $\mathrm{F}_{2}$, nearisogenic lines (NILs), backcrossed inbred lines (BIL), and recombinant inbred lines (RILs) [7-9], often in combination with bulked segregant analysis (BSA) [10-12]. BSA was originally developed to identify markers linked to disease resistance genes in plants, without the need of a genetic map, and consisted of genotyping two bulks, each containing individual plants with extreme phenotypes (i.e., resistant or susceptible). Polymorphic markers detected between the bulks are often located in genomic regions linked to the trait, and then candidate markers are screened across the original segregating population and additional lines and populations to confirm the marker-trait linkage [10]. These markers were also used, together with already available framework maps, to estimate the genomic position of disease resistance loci onto the consensus genetic map of common bean $[5,6,13]$.

Since the tagging of the Ur-4 bean rust (Uromyces appendiculatus) gene [11] many markers linked to genes and QTL controlling resistance to fungal, bacterial, and viral pathogens were developed by BSA approach using RAPD markers [5]. The conversion of RAPD to SCAR (sequence characterized amplified region) markers facilitated MAS (e.g., indirect phenotypic selection, selection of hypostatic genes, gene pyramiding) for the development of bean germplasm or cultivars with enhanced resistance or combined resistance to several pathogens [6]. However, the efficiency of MAS for breeding disease resistance in common bean is still hampered due to the dominance of many RAPD/SCAR markers, repulsion phase linkage between markers and dominant traits, continued need for progeny testing, and the realization that some markers are loosely linked in distinct mapping populations and/or ineffective in specific market classes or gene pools $[7,9,11,14-16]$. The development of novel disease resistance markers or the refinement of existing ones would benefit from the availability of highly polymorphic marker systems that generate codominant, more tightly linked, and broadly applicable markers.

Next-generation sequencing (NGS) allows the rapid development and application of genomics tools in plant breeding $[17,18]$. It enables the inexpensive and rapid discovery of DNA polymorphisms such as simple sequence repeats (SSR), insertion-deletions (InDel), and single nucleotide polymorphisms (SNP) in model crops $[19,20]$, including common bean [21,22]. Using the recently released reference genome sequence of common bean [23] markers can now be assigned physical genomic positions and candidate genes identified.

BSA and the NGS technology were recently applied to mapping and marker development for disease resistance loci in several crops [24-27]. By using restriction-site associated DNA (RAD) sequencing in a RIL population of lupin, markers tightly linked (0.5-0.9 cM) to anthracnose (Colletotrichum lupini) and phomopsis stem blight (Phomopsis leptostromiformis) resistances were rapidly developed [26,27]. In rice, a major QTL for partial resistance to rice blast (Magnaporthe oryzae) was identified in a RIL population subjected to whole-genome sequencing [25]. In order to minimize costs for NGS sequencing of complex genomes, BSA has also been coupled with transcriptional profiles from RNA-Seq data for mapping of QTL and mutant genes of agronomic interest in crops [28-30].

As a result of massive discovery of polymorphisms by NGS, high-throughput genotyping platforms for genomewide screening of SNPs were developed for crop species [20]. For common bean, a Golden Gate SNP assay containing 1,050 working SNPs, discovered by comparing SNPs between breeding lines Jalo EPP558 (Andean origin) and BAT93 (Middle American origin) was released [21]. Recently, the Common Bean Coordinated Agricultural Project (BeanCAP; www.beancap.org) consortium developed an Illumina Infinium BeadChip (BARCBEAN6K_3) containing 5,398 SNPs [31]. The SNPs were identified using whole-genome sequence analysis of 17 cultivars from different market classes and gene pools. This high-density SNP array provides greater whole genome coverage over previous marker systems. The BeanCAP diversity panel, consisting of over 500 common bean lines, was genotyped with the BARCBEAN6K_3 SNP chip and is being mainly utilized for association mapping studies and mapping select traits in bi-parental RIL populations [31-33].

The genome-wide SNP coverage of common bean provides an opportunity to discover SNPs underlying genomic regions of disease resistance traits previously identified by QTL mapping. A rapid method to discover or refine markers linked to common bean disease resistance genes would be the application of "in silico BSA", 
which consists of inspecting SNP variation among genotyped individuals, with known phenotype, at specific targeted genomic regions. This approach circumvents the need to develop mapping populations or genotype the original population from which the gene or QTL region was identified.

Resistance to BCMV and Bean common mosaic necrosis virus (BCMNV) is genetically well defined, and conditioned by a single dominant $(I)$ and four recessive $(b c-u, b c-1, b c-2$, $b c-3)$ genes [34]. Different alleles were identified for two of the loci $\left(b c-1^{2}\right.$ and $\left.b c-2^{2}\right)$. The chromosomal position of the $I$ gene, $b c-1^{2}$ and $b c-3$ genes map independently [6]. The $I$ gene confers immune or hypersensitive resistance to all strains of BCMV and BCMNV and is located on chromosome Pv02 [6] within a complex locus containing a cluster of nucleotide binding site-leucine rich repeat (NBS-LRR)type disease resistance genes (R-genes) [35]. A SCAR marker (SW13) linked to the $I$ gene was developed [36] and is widely used by bean breeders [6]. However, in several mapping populations, recombination between the SW13 marker and $I$ gene was detected [15]. Furthermore, due to the dominant nature of the marker there is still the need to perform progeny testing in order to identify homozygous resistant plants. Therefore, a codominant marker more tightly linked to the $I$ gene will be more informative than current dominant markers, and more accurate in predicting the disease reaction to BCMV.

As a proof of concept, in silico BSA was conducted on the BeanCAP panel to discover SNPs tightly linked to the chromosomal region underlying the $I$ gene, with the aim of developing codominant markers with broad applicability for MAS of the $I$ gene across the different market classes and gene pools of common bean. We discovered such SNPs and validated their linkage with the $I$ gene segregating in a RIL population. Finally, KASP (Kompetitive Allele Specific PCR) and CAPS (Cleaved Amplified Polymorphic Sequence) markers were developed from one of the SNP markers tightly linked with the $I$ gene and successfully validated in a subset of lines from the BeanCAP panel and in the RIL population.

\section{Results}

\section{Identification of candidate disease-resistance genes at the I gene}

The $I$ gene, as determined by the sequence of PCR products from primers for Phgp and Bng45 [35], is a locus located in the distal arm of chromosome Pv02 which encompasses a genomic region of $\sim 154 \mathrm{~kb}$, between positions 48,131,655 and 48,285,850. This locus contains seven putative disease-resistance loci belonging to the NBS-LRR gene family (Phvul.002G323000 to Phvul.002G323500, and Phvul.002G323800) which spans a $\sim 81.7 \mathrm{~kb}$ region $(48,183,168-48,264,877)$.

\section{Identification of SNP markers associated to BCMV resistance by in silico BSA}

Although, no SNPs were found in either the coding or intergenic regions of the NBS-LRR loci, 18 SNPs were found in the BeadChip that were in close proximity to the cluster of NBS-LRR R-genes at the $I$ gene (Figure 1). The closest and farthest SNPs mapped within $\sim 51$ and $\sim 355 \mathrm{~kb}$ from proximal (Phvul.002G323000) and distal (Phvul.002G323800) R-genes, respectively.

Initially, when the two in silico bulks were screened for contrasting alleles, most resistant genotypes, with a few exceptions, exhibited a homogenous haplotype. In contrast, susceptible genotypes exhibited multiple haplotypes (Figure 1).

Only six SNPs were consistently associated with the $I$ gene (Table 1). Further inspection for the remaining inoculated genotypes with known reaction to BCMV in the BeanCAP panel of 115 accessions (Additional file 1: Table S1) confirmed the association of the six SNPs to the phenotypic reaction to BCMV. Furthermore, the cosegregation of such SNPs with the $I$ gene were validated in silico on the entire BeanCAP panel and the RIL lines genotyped on the BARCBEAN6K_3 chip (Additional file 1: Table S1 and Additional file 2: Table S2). The contrasting SNPs define two distinct haplotypes, each associated with resistance or susceptibility.

\section{Greenhouse screening for BCMV resistance}

Greenhouse screening for BCMV/BCMNV resistance with strain NL-3 of BCMNV accurately discriminated between resistant genotypes [carrying the dominant allele $(I-)]$ and susceptible (ii) genotypes. Systemic necrosis in genotypes with the $I$ gene $(I-)$ developed as early as five days post inoculation (dpi), whereas vein necrosis (II $b c-1^{2} b c-1^{2}$ ) and local lesions (II $b c-u b c-u b c-2^{2} b c-2^{2}$ ) developed within $10 \mathrm{dpi}$.

All BCMV differentials and genotypes from the BeanCAP panel initially screened in the greenhouse reacted as expected (Tables 2 and 3). In addition, the remaining BeanCAP genotypes, with known or unknown reaction to NL-3 strain, showed distinct disease symptoms that correlated with a haplotype associated with $I$ gene resistance or susceptibility. All genotypes in this study appeared to be fixed for resistance (II) or susceptibility (ii), as all inoculated plants for each genotype displayed the same disease reaction.

\section{Conversion of select SNP into KASP and CAPS markers}

The closest SNP (A/G) that consistently cosegregated with the $I$ gene was ss715641188 ( 24.85-31.6 kb from $5^{\prime}$ and $3^{\prime}$ ends of Phvul.002G323800, respectively), and therefore it was targeted for development of KASP and CAPS markers. The $\mathrm{G}$ allele was associated with susceptible genotypes, whereas the resistant genotypes were 


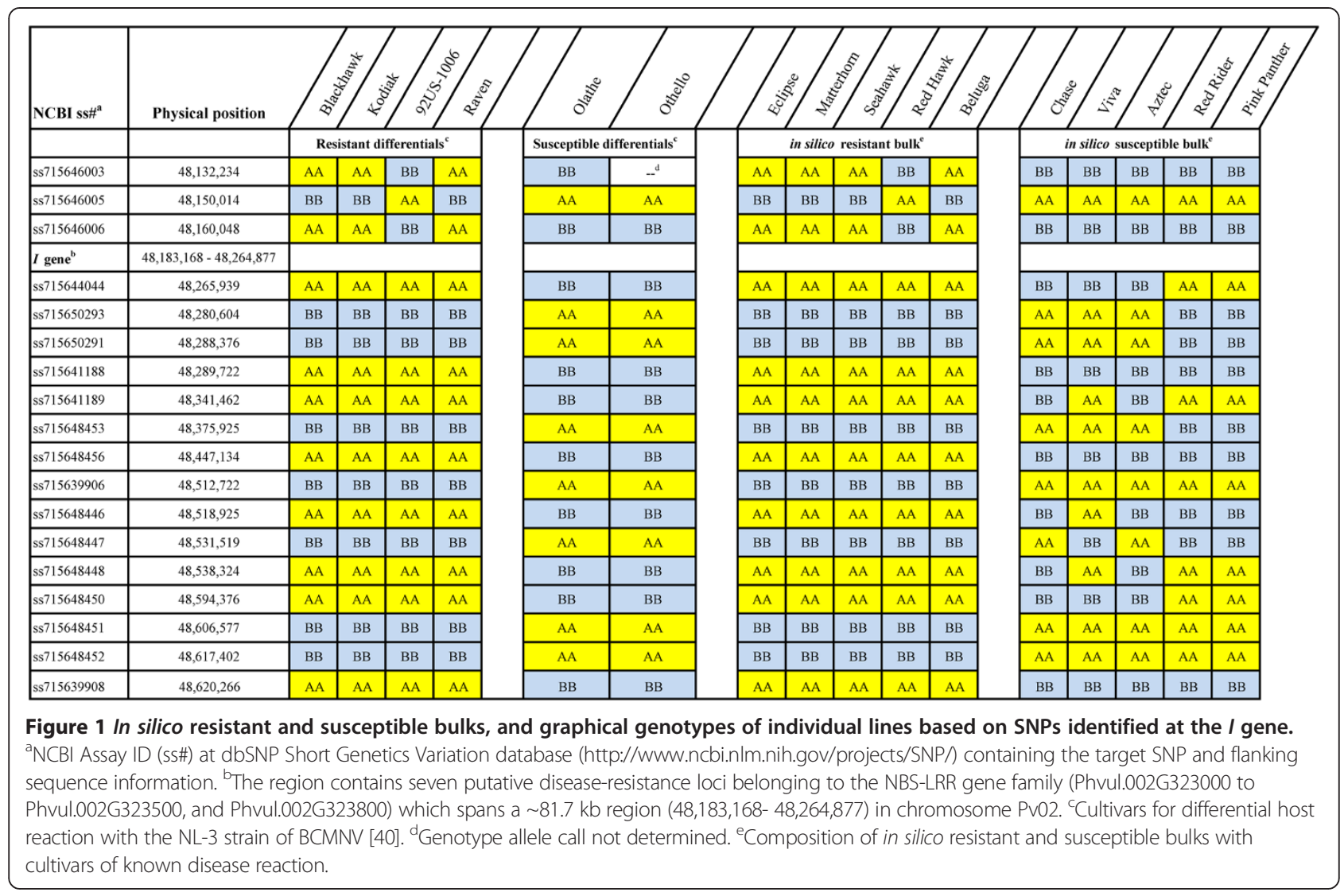

associated with A allele. The reference genotype G19833, used for whole genome sequencing of $P$. vulgaris, has the $\mathrm{G}$ allele. A KASP marker assay was developed, and select lines with known disease reaction to BCMV were initially screened. This allelic-specific assay detected each allele cosegregating with either I gene resistance (II) or susceptibility (ii) in all genotypes screened with the KASP marker (Tables 2, 3, and 4; Additional file 2: Table S2).

Amplification with the primers developed for the CAPS marker produced a single PCR amplicon of the expected $311 \mathrm{bp}$ size. Digestion of the PCR products for select lines with TaqI endonuclease detected the SNP associated with the BCMV-resistant allele (II), generating two bands of 201 and $110 \mathrm{bp}$. In contrast, PCR products from susceptible lines (ii) were not cut by TaqI due to the alteration of the restriction site (Figure 2). As expected, this marker was able to distinguish between resistant and susceptible genotypes in both the BeanCAP panel and the RIL population (Tables 2, 3, and 4; Additional file 2: Table S2).

\section{Linkage between marker and I gene locus}

Initially, we screened the BeanCAP genotypes and RIL population with SW13 marker, which is a dominant

Table 1 Summary of tightly linked SNP markers to the I gene associated to BCMV resistance

\begin{tabular}{|c|c|c|c|c|c|}
\hline BARCBEAN6K_3 SNP ID ${ }^{a}$ & $\begin{array}{c}\text { SNP } \\
(\mathrm{NCBI} s s \#)^{\mathrm{b}}\end{array}$ & $\begin{array}{l}\text { Susceptible } \\
\text { SNP allele }\end{array}$ & $\begin{array}{l}\text { Resistant } \\
\text { SNP allele }\end{array}$ & $\begin{array}{l}\text { Physical } \\
\text { position }\end{array}$ & $\begin{array}{l}\text { Distance from proximal and } \\
\text { distal NBS-LRR R-genes / locus }\end{array}$ \\
\hline sc01349In84482_14096_G_A_345640749 & ss715641188 & G & A & $48,289,722$ & $106,554 / 24,845$ \\
\hline sc00445In245016_77514_C_T_217829459 & ss715648456 & C & $\mathrm{T}$ & $48,447,134$ & $263,966 / 182,257$ \\
\hline sc00445In245016_132522_T_G_217884467 & ss715639906 & $\mathrm{T}$ & G & $48,512,722$ & $329,554 / 247,845$ \\
\hline sc00445In245016_228076_A_G_217980021 & ss715648451 & A & G & $48,606,577$ & $423,409 / 341,700$ \\
\hline sc00445In245016_240603_A_G_217992548 & ss715648452 & A & G & $48,617,402$ & $434,234 / 352,525$ \\
\hline sc00445In245016_243467_G_A_217995412 & ss715639908 & G & A & $48,620,266$ & $437,098 / 355,389$ \\
\hline
\end{tabular}

${ }^{a}$ Original SNP name in the BARCBEAN6K_3 SNP BeadChip.

${ }^{\mathrm{b}} \mathrm{NCBI}$ Assay ID (ss\#) at dbSNP Short Genetics Variation database (http://www.ncbi.nlm.nih.gov/projects/SNP/) containing the target SNP and flanking sequence information. 'The region contains seven putative disease-resistance loci belonging to the NBS-LRR gene family (Phvul.002G323000 to Phvul.002G323500, and Phvul.002G323800) which spans a $\sim 81.7 \mathrm{~kb}$ region $(48,183,168-48,264,877)$ in chromosome Pv02. 
Table 2 Common bean genotypes of the BeanCAP panel, from Middle American origin, screened for BCMV resistance in the greenhouse and for markers linked to the I gene for resistance to BCMV

\begin{tabular}{|c|c|c|c|c|c|c|}
\hline Type & Genotype & Disease reaction $^{a}$ & Genotype allele call for SNP BeadChip ${ }^{b}$ & SW13 ${ }^{c}$ & KASP $^{d}$ & CAPS $^{\mathrm{e}}$ \\
\hline \multirow[t]{9}{*}{ Black } & $A-55$ & $R$ & NA & + & $A$ & A \\
\hline & Black Magic & $\mathrm{R}$ & AA & + & A & A \\
\hline & Blackhawk & R & AA & + & A & A \\
\hline & Eclipse & R & AA & + & A & A \\
\hline & Jaguar & $\mathrm{R}$ & AA & + & A & A \\
\hline & Phantom & $\mathrm{R}$ & NA & + & A & A \\
\hline & Raven & NR & AA & + & A & A \\
\hline & UI-906 & $\mathrm{R}$ & AA & + & A & A \\
\hline & Zorro & R & AA & + & A & A \\
\hline Black mottle & Orca & R & AA & + & A & A \\
\hline \multirow[t]{6}{*}{ Great Northern } & ABC-Weihing & R & AA & - & A & A \\
\hline & Beryl R & $\mathrm{R}$ & AA & + & A & A \\
\hline & GN9-4 & $\mathrm{R}$ & $A A$ & + & A & A \\
\hline & $J M-24$ & $\mathrm{R}$ & AA & + & A & A \\
\hline & Matterhorn & $\mathrm{R}$ & $\mathrm{AA}$ & + & A & A \\
\hline & Orion & $\mathrm{R}$ & AA & + & A & A \\
\hline \multirow[t]{5}{*}{ Navy } & Avalanche & R & AA & + & A & A \\
\hline & Avanti & $\mathrm{R}$ & $\mathrm{AA}$ & + & A & A \\
\hline & Huron & $\mathrm{R}$ & NA & + & A & A \\
\hline & Newport & $\mathrm{R}$ & AA & + & A & A \\
\hline & Seahawk & $\mathrm{R}$ & AA & + & A & A \\
\hline Pink & USWA-61 & $\mathrm{R}$ & AA & + & A & A \\
\hline \multirow[t]{9}{*}{ Pinto } & Baja & R & AA & + & A & A \\
\hline & Buster & $\mathrm{R}$ & $\mathrm{AA}$ & - & A & A \\
\hline & $J M-126$ & $\mathrm{R}$ & AA & + & A & A \\
\hline & Kodiak & R & AA & + & A & A \\
\hline & Quincy & $\mathrm{R}$ & AA & + & A & A \\
\hline & Santa Fe & $\mathrm{R}$ & $\mathrm{AA}$ & + & A & A \\
\hline & USPT-ANT-1 & $\mathrm{R}$ & NA & - & A & A \\
\hline & USPT-CBB-1 & R & AA & - & A & A \\
\hline & USPT-WM-1 & $\mathrm{R}$ & $\mathrm{AA}$ & + & A & A \\
\hline \multirow[t]{2}{*}{ Small red } & DOR 364 & $\mathrm{R}$ & AA & - & A & A \\
\hline & Rojo Chiquito & $\mathrm{R}$ & AA & + & A & A \\
\hline \multirow[t]{9}{*}{ Great Northern } & ABCP-8 & S & BB & - & G & B \\
\hline & BelNeb-RR-1 & S & BB & - & G & $B$ \\
\hline & BelNeb-RR-2 & S & BB & - & G & B \\
\hline & Chase & S & BB & - & G & B \\
\hline & Emerson & S & NA & - & G & B \\
\hline & GN Harris & S & BB & - & G & B \\
\hline & GN\#1Sel27 & S & BB & - & G & B \\
\hline & Sapphire & S & BB & - & G & B \\
\hline & Starlight & S & BB & - & $G$ & B \\
\hline
\end{tabular}


Table 2 Common bean genotypes of the BeanCAP panel, from Middle American origin, screened for BCMV resistance in the greenhouse and for markers linked to the I gene for resistance to BCMV (Continued)

\begin{tabular}{|c|c|c|c|c|c|c|}
\hline \multirow[t]{8}{*}{ Pink } & $6 \mathrm{R}-42$ & $S$ & BB & - & G & B \\
\hline & Harold & S & $\mathrm{BB}$ & - & G & B \\
\hline & ROG 312 & S & $\mathrm{BB}$ & - & G & B \\
\hline & Roza & S & $\mathrm{BB}$ & - & G & B \\
\hline & Sutter Pink & S & NA & - & G & B \\
\hline & UI-537 & S & $\mathrm{BB}$ & - & G & B \\
\hline & Viva & S & $\mathrm{BB}$ & - & G & B \\
\hline & Yolano & S & $\mathrm{BB}$ & - & G & B \\
\hline \multirow[t]{23}{*}{ Pinto } & AC Pintoba & S & $\mathrm{BB}$ & - & G & B \\
\hline & Apache & S & $\mathrm{BB}$ & - & G & B \\
\hline & Arapaho & S & $\mathrm{BB}$ & - & G & B \\
\hline & Aztec & S & BB & - & G & B \\
\hline & Bill Z & S & $\mathrm{BB}$ & - & G & B \\
\hline & Burke & $S$ & $\mathrm{BB}$ & - & G & B \\
\hline & Common Pinto & S & $\mathrm{BB}$ & - & G & B \\
\hline & Fiesta & S & BB & - & G & B \\
\hline & Grand Mesa & S & $\mathrm{BB}$ & - & G & B \\
\hline & Holberg & $S$ & BB & - & G & B \\
\hline & La Paz & S & $\mathrm{BB}$ & - & G & B \\
\hline & Medicine Hat & S & BB & - & G & B \\
\hline & Montrose & $S$ & $\mathrm{BB}$ & - & G & B \\
\hline & Nodak & S & $\mathrm{BB}$ & - & G & B \\
\hline & NW-590 & $S$ & $\mathrm{BB}$ & - & G & B \\
\hline & Othello & $N R$ & $\mathrm{BB}$ & - & G & B \\
\hline & Ouray & S & $\mathrm{BB}$ & - & G & B \\
\hline & Pindak & $S$ & NA & - & G & B \\
\hline & Sierra & $S$ & $\mathrm{BB}$ & - & G & B \\
\hline & Topaz & S & $\mathrm{BB}$ & - & G & B \\
\hline & UI-111 & $S$ & $\mathrm{BB}$ & - & G & B \\
\hline & UI-114 & S & $\mathrm{BB}$ & - & G & B \\
\hline & UI-196 & S & BB & - & G & B \\
\hline \multirow[t]{2}{*}{ Small Red } & Garnet & S & $\mathrm{BB}$ & - & G & B \\
\hline & USRM-20 & S & $\mathrm{BB}$ & - & G & B \\
\hline
\end{tabular}

${ }^{\mathrm{a}} \mathrm{R}=$ Resistance (symptoms include systemic necrosis, mainly; and vein necrosis and local lesions, if $I$ gene was protected by $b c$ recessive genes); $\mathrm{S}=$ Susceptibility (systemic mosaic, or mild mosaic in the presence of $b c-1^{2}$ gene). NR $=$ no disease reaction to the NL-3 strain of BCMNV due to the interaction of $I$ allele and $b c-3$ gene (R) or $b c-2^{2}$ gene alone (S).

${ }^{\mathrm{b}}$ Automated genotype calls obtained from data of BARCBEAN6K_3 SNP BeadChip. NA = genotype not available. Sutter Pink is not part of the BeanCAP panel. ${ }^{c}$ Marker present $=+$; marker absent $=$-.

${ }^{d}$ KASP genotype calls. $A=$ homozygous for SNP allele $A ; G=$ homozygous for SNP allele $G$.

'The CAPS marker yields two alleles. The resistant allele has two bands ( 201 and $110 \mathrm{bp}$ ), whereas the susceptible allele has a single band ( $311 \mathrm{bp}$ ). A = homozygous for resistant allele $I$; $B=$ homozygous for susceptible allele $i$.

marker in coupling phase with the $I$ gene. In general, the presence or absence of SW13 marker corresponded to the known phenotype for plants screened in the greenhouse (Tables 2 and 3). However, the SW13 marker was not detected in five resistant genotypes from the subset of the BeanCAP collection, belonging to races Durango/Jalisco of the Middle American gene pool; also, the SW13 marker was present in a single susceptible RIL individual (GM-23; Additional file 2: Table S2) .

All 122 genotypes screened in the greenhouse for BCMV resistance (Tables 2 and 3), and 90 RILs from the 
Table 3 Common bean genotypes of the BeanCAP panel, from Andean origin, screened for BCMV resistance in the greenhouse and for markers linked to the $I$ gene for resistance to BCMV

\begin{tabular}{|c|c|c|c|c|c|c|}
\hline Type & Genotype & Disease reaction $^{a}$ & Genotype allele call for SNP BeadChip ${ }^{b}$ & SW13c & KASP $^{d}$ & CAPS $^{\mathrm{e}}$ \\
\hline \multirow[t]{6}{*}{ Cranberry } & Capri & $\mathrm{R}$ & AA & + & A & A \\
\hline & Cardinal & $\mathrm{R}$ & AA & + & A & A \\
\hline & Dolly & R & $\mathrm{AA}$ & + & A & A \\
\hline & Etna & $\mathrm{R}$ & AA & + & A & A \\
\hline & Krimson & R & AA & + & A & A \\
\hline & UI-51 & $\mathrm{R}$ & AA & + & A & A \\
\hline \multirow[t]{7}{*}{ Dark Red Kidney } & Fiero & $\mathrm{R}$ & $\mathrm{AA}$ & + & $?$ & A \\
\hline & Isles & $\mathrm{R}$ & AA & + & A & A \\
\hline & Majesty & $\mathrm{R}$ & $\mathrm{AA}$ & + & $A / G$ & A \\
\hline & Montcalm & $\mathrm{R}$ & AA & + & A & A \\
\hline & Red Hawk & $\mathrm{R}$ & AA & + & A & A \\
\hline & Royal Red & $\mathrm{R}$ & AA & + & A & A \\
\hline & USDK-CBB-15 & $\mathrm{R}$ & AA & + & A & A \\
\hline \multirow[t]{10}{*}{ Light Red Kidney } & Badillo & R & $\mathrm{AA}$ & + & A & A \\
\hline & Blush & $\mathrm{R}$ & AA & + & A & A \\
\hline & CELRK & R & AA & + & A & A \\
\hline & Chinook 2000 & R & $\mathrm{AA}$ & + & A & A \\
\hline & Drake & R & AA & + & A & A \\
\hline & $\mathrm{K}-42$ & R & AA & + & A & A \\
\hline & Cardinal & $\mathrm{R}$ & $\mathrm{AA}$ & + & A & A \\
\hline & Pink Panther & $\mathrm{R}$ & $\mathrm{AA}$ & + & A & A \\
\hline & Red Kanner & $\mathrm{R}$ & $\mathrm{AA}$ & + & A & A \\
\hline & Red Kloud & $\mathrm{R}$ & AA & + & A & A \\
\hline \multirow[t]{3}{*}{ White kidney } & Beluga & R & AA & + & A & A \\
\hline & Silver Cloud & $\mathrm{R}$ & $\mathrm{AA}$ & + & A & A \\
\hline & USWK-CBB-17 & $\mathrm{R}$ & AA & + & A & A \\
\hline \multirow[t]{5}{*}{ Cranberry } & Cran-09 & S & $\mathrm{BB}$ & - & G & B \\
\hline & G122 & S & $\mathrm{BB}$ & - & G & B \\
\hline & G19833 & S & NA & - & G & B \\
\hline & Red Rider & S & $\mathrm{BB}$ & - & G & B \\
\hline & Taylor Hort & S & BB & - & G & B \\
\hline \multirow[t]{2}{*}{ Dark Red Kidney } & CDRK & S & BB & - & G & B \\
\hline & Charlevoix & S & $\mathrm{BB}$ & - & G & B \\
\hline \multirow[t]{2}{*}{ Light Red Kidney } & Sacramento & S & BB & + & G & B \\
\hline & UC Red Kidney & S & $\mathrm{BB}$ & - & G & B \\
\hline Pink cranberry & Ind. Jamaica Red & S & BB & - & G & B \\
\hline \multirow[t]{2}{*}{ Purple speckled } & Jesca & S & NA & - & G & B \\
\hline & KIJIVU & S & NA & - & G & B \\
\hline Red & CANADA & S & NA & - & G & B \\
\hline \multirow[t]{4}{*}{ Red mottle } & CAL-143 & S & BB & - & G & B \\
\hline & ICA Quimbaya & S & BB & - & G & B \\
\hline & Pompadour B & S & BB & - & G & B \\
\hline & ROZI KOKO & S & NA & - & G & B \\
\hline
\end{tabular}


Table 3 Common bean genotypes of the BeanCAP panel, from Andean origin, screened for BCMV resistance in the greenhouse and for markers linked to the I gene for resistance to BCMV (Continued)

\begin{tabular}{|c|c|c|c|c|c|c|}
\hline White Kidney & Lassen & $\mathrm{S}$ & $\mathrm{BB}$ & - & G & B \\
\hline \multirow[t]{3}{*}{ Yellow } & BUKOBA & $S$ & NA & - & G & B \\
\hline & Jalo EEP558 & $S$ & $\mathrm{BB}$ & - & G & B \\
\hline & Myasi & $S$ & $\mathrm{BB}$ & - & G & B \\
\hline
\end{tabular}

${ }^{\mathrm{a}} \mathrm{R}=$ Resistance (symptoms include systemic necrosis, mainly; and vein necrosis and local lesions, if $I$ gene was protected by $b c$ recessive genes); $\mathrm{S}=\mathrm{Susceptibility}$ (systemic mosaic, or mild mosaic in the presence of $b c-1^{2}$ gene). NR $=$ no disease reaction to the NL-3 strain of BCMNV due to the interaction of $I$ allele and $b c-3$ gene $(\mathrm{R})$ or $b c-2^{2}$ gene alone $(\mathrm{S})$.

${ }^{b}$ Automated genotype calls obtained from data of BARCBEAN6K_3 SNP BeadChip. NA = genotype not available. G19833 (used as reference for whole-genome sequence of common bean) is not part of the BeanCAP panel. In addition, African lines: Jesca, KIJIVU, CANADA, ROZI KOKO, and BUKOBA, belong to the Andean Diversity Panel of common bean.

${ }^{\mathrm{C}}$ Marker present $=+$; marker absent $=$-.

${ }^{d}$ KASP genotype calls. $A=$ homozygous for SNP allele $A ; G=$ homozygous for SNP allele $G ; ?=$ failed genotyping reaction. $A / G=$ heterozygous.

'The CAPS marker yields two alleles. The resistant allele has two bands (201 and $110 \mathrm{bp}$ ), whereas the susceptible allele has a single band ( $311 \mathrm{bp}$ ). $\mathrm{A}=\mathrm{homozygous}$ for resistant allele $I ;$ B $=$ homozygous for susceptible allele ii.

G122 $\times$ Montcalm population, were also genotyped with the KASP and CAPS markers. The KASP assay distinguished resistant and susceptible genotypes in all cases. Likewise, the CAPS marker completely distinguished resistant (II) or susceptible (ii) genotypes. Finally, based on the cosegregation of phenotype and SNP markers in the RIL population, the SNP was tightly linked to the genomic region underlying the $I$ gene as no recombinant individuals were detected.

\section{Discussion}

We used in silico BSA to discover SNP variation within the genomic region associated with BCMV resistance in a diverse collection of germplasm. This approach led to the development of a tightly linked-codominant genetic marker. Our results demonstrate that we can take advantage of the extensive information of gene/QTL mapping for disease resistance traits in common bean [5,6] and the power of in silico BSA of NGS data as a rapid and low-cost approach for marker development.

The rate of marker discovery in common bean was hampered in the past by a lack of a reference genome sequence [23]. Now, a high-density SNP array platform facilitates high-throughput genotyping. Multiple diversity panels containing hundreds of lines from diverse breeding programs have been densely genotyped with thousands of markers and can now be applied to genetic studies for which multiple sets of phenotypic data can be collected. Here the availability of these genomics resources allowed us to map the physical position of the $I$ gene. The region underlying the $I$ gene contains a cluster of seven NBSLRR R-genes, spanning $\sim 81.7 \mathrm{~kb}$ region and confirms previous findings [35] that suggested that this region was enriched for NBS-LRR-type sequences.

BSA, coupled with NGS genotyping pipelines, has been applied in other crops for development of markers linked to disease resistance genes [24-27] using contrasting (i.e., resistant vs. susceptible) pools of RIL populations. In several instances, specific RIL populations segregate for only one or few genetic traits. In contrast, we applied in silico BSA to the BeanCAP panel, containing 506 lines genotyped on an Infinium 6K SNP BeadChip, which circumvented the need to develop a bi-parental mapping population. In addition, the use of the diversity panel allowed us to explore many more recombination events. Most SCAR markers linked to disease resistance

Table 4 Summary of markers linked to the I gene for resistance to BCMV screened on the RIL population derived from G122 × Montcalm

\begin{tabular}{|c|c|c|c|c|c|}
\hline Genotype $^{a}$ & Number of lines ${ }^{b}$ & Genotype allele call for SNP BeadChip ${ }^{c}$ & SW13 ${ }^{d}$ & KASP & CAPS $^{f}$ \\
\hline Montcalm (R) & & $\mathrm{AA}$ & + & A & A \\
\hline G122 (S) & & BB & - & G & B \\
\hline Resistant RILs & 63 & All AA & All + & All A & All A \\
\hline Susceptible RILs & 27 & All BB & $1+/ 26-$ & All G & All B \\
\hline
\end{tabular}

${ }^{\mathrm{a}} \mathrm{R}=$ Resistance (symptoms include systemic necrosis, mainly due to unprotected / gene); $\mathrm{S}=$ Susceptibility (systemic mosaic from lack of $/$ gene or any recessive resistance genes).

${ }^{\mathrm{b}}$ Number of lines screened with markers SW13, KASP, and CAPS in this study.

'Automated genotype calls obtained from data of BARCBEAN6K_3 SNP BeadChip.

${ }^{\mathrm{d}}$ Marker present $=+$; marker absent $=-$.

EASP genotype calls. $A=$ homozygous for SNP allele $A ; G=$ homozygous for SNP allele $G$.

${ }^{\mathrm{f}}$ The CAPS marker yields two alleles. The resistant allele has two bands (201 and $110 \mathrm{bp}$ ), whereas the susceptible allele has a single band ( $311 \mathrm{bp}$ ). $\mathrm{A}=\mathrm{homozygous}$ for resistant allele $I$; $\mathrm{B}=$ homozygous for susceptible allele ii. 


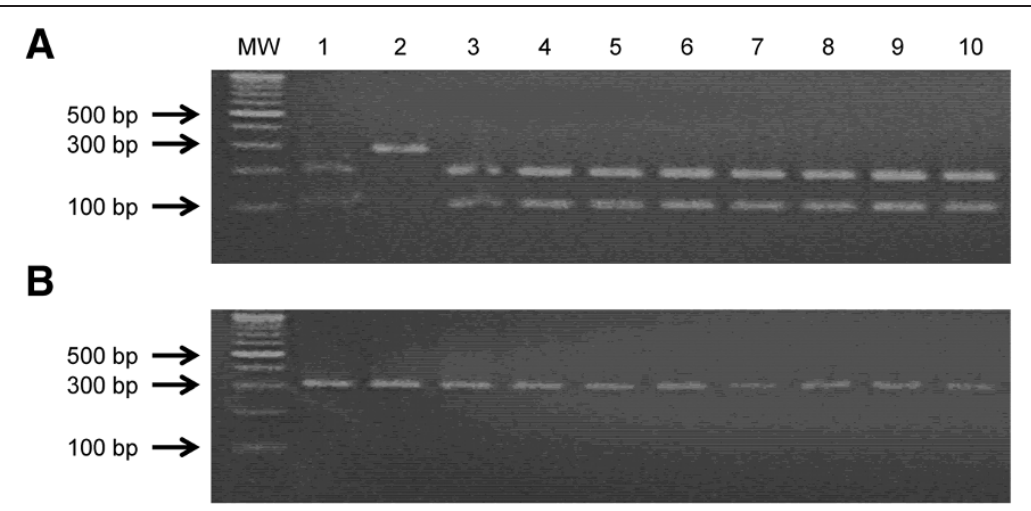

Figure 2 Restriction digestion pattern for allele-specific CAPS marker targeting SNP ss715641188 linked to / gene controlling resistance to BCMV. MW =100 bp DNA ladder. Digestion of PCR amplicon (311 bp) with Taql generates products of 201 and 110 bp. (A) 1. BCMV-resistant line Montcalm (I), 2. BCMV-susceptible line G122 (ii), 3-10. Resistant RILs. (B). 1-10. Susceptible RILs.

traits in common bean (http://www.ars.usda.gov/SP2UserFiles/person/3848/PDF/Miklas_2011/SCAR\%20Markers\% 202010.pdf) were developed by BSA using RAPD markers and RIL populations, many of them derived from wide crosses [5,6]. Consequently, several markers were of use only in specific populations, market classes, or gene pools (e.g., SCAR marker SAS8, for Beet Curly Top virus resistance, works only in germplasm from Andean origin) $[5,6,14]$. The SNPs, and subsequent KASP and CAPS markers cosegregated with the $I$ gene in the full BeanCAP panel and a RIL population (Additional file 1: Table S1 and Additional file 2: Table S2).

Although the SW13 marker is widely used in common bean breeding programs and seems to work across diverse material, recombination between the marker and $I$ gene has been detected in distinct mapping populations, ranging from 1.3 to $8.9 \mathrm{cM}[15,36,37]$. In fact, five resistant members of the diversity panel were assigned as susceptible and a single susceptible RIL line was erroneously scored as resistant, based on the absence or presence of the dominant SW13 marker, respectively. The latter event is of greater consequence during breeding since a truly susceptible line might be advanced in the program even though it otherwise had the unwanted genotype $(i i)$. The new markers described here resolve those issues for breeders.

A BLAT search on the reference genome database revealed that the SW13 marker was distributed along several common bean chromosomes. The closest sequence hits [Expect (E)-value 1.00 ${ }^{-192}$, identity $94.4 \%$ (357/358 bp), and E-value $1.00^{-103}$, identity $94.3 \%$ (200/212 bp)] for partial sequences of SW13 marker on chromosome Pv02 are approximately between 6 and $12 \mathrm{Mbp}$ away from the $I$ gene. The position of the ss715641188 SNP to the closest R-gene model (Phvul.002G323800) is $\sim 25 \mathrm{~kb}$, which suggests the chance for recombination between the SNP marker and the most proximal R-gene is very minimal.
We have demonstrated that BSA coupled with NGS technology can accurately identify SNPs linked to a disease resistance trait, which in turn enabled the development of robust marker systems. The approach to tag monogenic and quantitative traits of agronomic interest in common bean previously relied on the application of BSA using AFLP, RAPD, or SSR markers, but this task proved to be tedious and time consuming. The main advantage of NGS data is that sequence surrounding SNPs or any sequenced marker is readily available and can be assigned to a physical position on the reference genome; thus, their conversion to effective genetic markers is relatively straight forward.

We decided to target the closest candidate SNP (ss715641188), that consistently cosegregated with $I$ gene, for conversion to a cost-effective genetic KASP and CAPS markers. Both genotyping technologies accurately predicted the disease response phenotype. In addition, these markers are codominant and thus are able to distinguish between heterozygous and homozygous resistant plants. Thus, the implementation of either KASP or CAPS screening procedure can select homozygous resistant plants during early breeding cycles (e.g., $\mathrm{F}_{2}$ selection). This will save at least four months of progeny testing for this phenotype [15].

BCMV is one of the most important viral diseases of common bean worldwide, and the combination of resistance genes with different mechanisms of action offers a more durable resistance compared to single gene resistance [38]. In addition, where necrotic strains of BCMV or BCMNV are present, plants with the $I$ gene need to be protected from the strong, hypersensitive response by the addition of $b c$ recessive genes [8]. One of the most desirable gene combinations is that of $I+b c-3$. However, the action of the $I$ gene is masked by $b c-3$, and therefore direct selection for $I$ gene is not possible [38]. Thus, these new markers offer an opportunity for more efficient 
indirect selection of the $I$ gene in the presence of $b c$ recessive genes and greatly facilitates pyramiding the appropriate combination of genes.

\section{Conclusions}

This is the first BSA approach that makes use of the wealth of information of gene/QTL mapping for disease resistance traits in common bean and exploits the SNP variation underlying the chromosomal region associated with the $I$ gene in a diversity panel. Many disease resistance-markers previously developed for common bean are not ideal for MAS (e.g., dominant, loose linkage, market class-specific). In this study, we were able to identify two distinct haplotypes each associated to resistance or susceptibility to BCMV across genetically diverse germplasm. Since the physical position and sequences flanking the informative SNPs are known, the task for development of robust codominant marker systems is simplified. In addition, the availability of a densely phenotyped/genotyped diversity panel guarantees that developed markers are applicable to diverse germplasm, thus circumventing the need for developing specific bi-parental mapping populations.

\section{Methods}

\section{Plant materials and DNA isolation}

A total of 122 diverse genotypes of common bean, including 115 lines of the BeanCAP and five African lines of the Andean Diversity Panel (ADP; http://arsfttbean. uprm.edu/bean/?page_id=179), from different market classes, belonging to both Middle American (black, navy, small white, Great northern, pink, pinto, small red) and Andean (cranberry, dark red kidney, light red kidney, white kidney, red, red mottle, purple speckled, yellow) gene pools, with known or unknown disease reaction to BCMV were evaluated in this study (Tables 2 and 3; Additional file 1: Table S1). The universal BCMV-susceptible cultivar Sutter Pink, and the line G19833 (which was used as reference for whole-genome sequence of $P$. vulgaris) were utilized in this study. In addition, an advanced $F_{2: 5}$ derived RIL [GM; G122 (susceptible) $\times$ Montcalm (resistant)] population of 98 lines, and the parental lines, were also included in this study for validation of marker-I gene cosegregation (Additional file 2: Table S2). The GM population shows distorted segregation in favor of the $I$ gene, which is a common occurrence previously documented in distinct RIL populations [32,39].

Genomic DNA was extracted from the first trifoliate leaves of two-week old plants using the DNeasy Plant Mini Kit (Qiagen, Valencia, CA) according to the manufacturer's protocol. For marker validation, DNA was extracted from pooled-trifoliate leaves of up to four plants per genotype before viral inoculation procedure.

\section{Plant genotyping and in silico BSA}

Five-hundred and six genotypes that compose the BeanCAP panel were previously genotyped with the Illumina BARCBEAN6K_3 Infinium SNP BeadChip, which includes allelic data for 5,398 SNP. Genotyping was performed according to manufacturer's recommendations at the USDA Soybean Genomics and Improvement Lab, Beltsville, MD, and data generated for each genotype was used for allele calling using GenomeStudio Software v2011.1 (Illumina, San Diego, CA).

The physical position for all SNPs in the BeadChip in the whole genome sequence of common bean (www.phytozome.net/commonbean) is known. The genomic region for the $I$ gene was identified by querying the sequences of markers Phgp and Bng45 [35], flanking the region associated to $\mathrm{BCMV}$ resistance, against the $P$. vulgaris reference genome database in Phytozome using BLAT search.

BCMV differentials [i.e., Blackhawk (II), Kodiak (II $\left.b c-1^{2} b c-1^{2}\right)$, 92US-1006 (II $\left.b c-2^{2} b c-2^{2}\right)$, Raven (II $b c-3 b c-3$ ), Olathe (ii $b c-1^{2} b c-1^{2}$ ), and Othello (ii $b c-2^{2} b c-2^{2}$ ) [40] and ten BeanCAP genotypes with known disease reactions to strain NL-3 of BCMNV were divided into resistant and susceptible in silico bulks. Resistant genotypes (dominant II gene) included were: Eclipse, Matterhorn, Seahawk, Red Hawk, and Beluga; whereas susceptible genotypes (recessive $i i$ gene) included were: Chase, Viva, Aztec, Red Rider, and Pink Panther. Then, each bulk was inspected for SNP variation at the $I$ gene and flanking regions. Contrasting SNP alleles between the in silico bulks were considered as putative markers linked to BCMV resistance. After the initial in silico BSA, the rest of the BeanCAP panel, including the RIL population, was inspected for haplotypes defining the resistant and susceptible groups (Additional file 1: Table S1 and Additional file 2: Table S2).

\section{BCMV resistance screening}

Seventy five and 47 genotypes from both Middle American and Andean origin, respectively, with either the resistantor susceptible-haplotype were screened in the greenhouse for I gene resistance with NL-3 strain of BCMNV. The Andean G19833 line and Middle American Sutter Pink cultivar were also screened. The RIL population was previously screened for BCMV resistance (unpublished data).

BCMNV NL-3 strain was maintained in infected seeds of Sutter Pink, and young leaflets of plants showing mosaic symptoms were used as inoculum. The disease reaction of each genotype was verified by mechanical inoculation with the virus [34,38], and cultivars for BCMV differential genotypes were used as controls [40]. Homozygous recessive (ii) plants without recessive genes develop systemic mosaic symptoms, but those homozygous plants carrying the $b c-u b c-1^{2}$ or $b c-u b c-2^{2}$ develop mild mosaic or no symptoms, respectively. In 
contrast, plants carrying a dominant allele (I-) develop systemic necrosis and eventually die, and depending upon the presence of other recessive $b c$-genes plants develop vein necrosis (II $\left.b c-1^{2} b c-1^{2}\right)$ or local lesions (II $b c-u b c-u b c-2^{2} b c-2^{2}$ ). However, plants with the $I$ gene in the homozygous background of $b c-3$ gene develop no symptoms [38].

In short, the primary leaves of four 10-day seedlings of each genotype, growing in a $10 \times 10 \mathrm{~cm}$ plastic pot containing Sunshine Professional Growing Mix (Sun Gro Horticulture, Bellevue, WA) were rub inoculated with the viral inoculum, and incubated in the greenhouse (24-28 ${ }^{\circ} \mathrm{C}, 14-\mathrm{h}$ photoperiod). The disease reaction was periodically assessed five dpi until 4-weeks dpi, and each genotype was classified as susceptible or resistant according to the symptoms described above.

\section{Development and validation of genetic KASP and CAPS markers}

Only the closest SNP marker [ss715641188 (sc01349 In84482_14096_G_A_345640749)] to the I gene was targeted for conversion to KASP (LGC Genomics, Beverly, MA) and CAPS markers. Allele-specific reverse KASP primers (BCMV_48289723_A, BCMV_48289723_G), and a common forward primer (BCMV_48289723_F) were designed (Ag-Biotech, San Juan Bautista, CA) (Table 5) and initially validated in the genotyped BCMV differentials, G19833, and the RIL parental lines. The KASP genotyping reaction and PCR thermocycling conditions were carried out according to manufacturer's recommendations (LGC Genomics, Beverly, MA). PCR reaction mixture was carried out in a $10 \mu \mathrm{l}$-volume consisting of $2.5 \mu \mathrm{l}$ DNA (10 $\mathrm{ng} \mathrm{\mu l}^{-1}$ ), $2.5 \mu \mathrm{l}$ 2X KASP Master mix v4.0, and $0.07 \mu \mathrm{l} 72 \mathrm{X}$ KASP Primer mix. PCR amplification and fluorescent end-point genotyping was carried out in a LightCycler 480 thermocycler (Roche Applied Science, Indianapolis, IN). Primer sequences were used as queries in a BLAST search to check primer specificity against the common bean genome sequence database.
For CAPS marker (Table 5), the SNP was analyzed for potential restriction enzyme recognition sites using the SGN CAPS designer (http://sgn.cornell.edu/tools/ caps_designer/caps_input.pl). Several restriction endonucleases were found to recognize the SNP (A/G) and neighboring bases, and TaqI was chosen for the CAPS genotyping assay as it is commonly used and low-cost. TaqI recognizes the restriction site TCGA and cleaves the resistance allele but not the susceptible allele due to the alteration of the restriction site (i.e., TCGG) by the SNP. A PCR primer pair (BCMV_48289723_CAPS) flanking the SNP was designed using Geneious R7 (Biomatters Inc., San Francisco, CA) to produce a PCR amplicon of $311 \mathrm{bp}$. Primer specificity was checked against the common bean genome sequence database. PCR reaction mix consisted of $1 \mathrm{X}$ Go Taq Reaction buffer, $1.5 \mathrm{mM} \mathrm{MgCl}_{2}, 0.2 \mathrm{mM}$ of each dNTP's, $0.2 \mu \mathrm{M}$ each primer, $20 \mathrm{ng}$ genomic DNA, and $1 \mathrm{U}$ of Go Taq DNA polymerase, in a $25 \mu \mathrm{l}$ final volume. All reagents were purchased from Promega (Madison, WI). PCR was performed on an GeneAmp PCR System 9700 thermocycler (Applied Biosystems, Foster City, CA) with an initial denaturation at $94^{\circ} \mathrm{C}$ for $5 \mathrm{~min}$; followed by 35 cycles of $94^{\circ} \mathrm{C}$ for $30 \mathrm{~s}, 58^{\circ} \mathrm{C}$ for $30 \mathrm{~s}$, and $72^{\circ} \mathrm{C}$ for $30 \mathrm{~s}$; final step of $72^{\circ} \mathrm{C}$ for $5 \mathrm{~min}$. Initially, PCR products were separated and visualized on a $1 \%$ agarose gel to verify presence and correct size of PCR amplicon. A five- $\mu \mathrm{l}$ aliquot of PCR products were digested in a $20 \mu \mathrm{l}$ reaction containing $1 \mathrm{X}$ FastDigest Green buffer, and $1 \mu \mathrm{l}$ FastDigest TaqI enzyme (Thermo Scientific, Waltham, MA). The reaction was incubated at $65^{\circ} \mathrm{C}$ for $15 \mathrm{~min}$ on the thermocycler, and digestion products were separated and visualized on a $2 \%$ agarose gel. The resistant allele is cleaved by TaqI generating two bands of 201 and $110 \mathrm{bp}$.

After initial validation of KASP and CAPS markers, all 122 genotypes (including those from the BeanCAP and ADP panels, Sutter Pink and G19833), RIL population $(n=92)$ and its parental lines were genotyped with the above markers. In addition, plants were also screened

Table 5 Sequences of primers used for genotyping BCMV resistance conferred by the $I$ gene

\begin{tabular}{llc}
\hline Marker & Primers (5'-3') & Physical position \\
\hline SW13 marker & CACAGCGACATTAATTTCCTTTC & Multiple hits in the genome \\
(Melotto et al., 1996) [36] & CACAGCGACAGGAGGAGCTTATTA & \\
KASP marker (without tail sequences), & \\
BCMV_48289723_F & CCCTAATTCACTTTCCGAGTAAGAGAAGC & $48,289,632$ \\
BCMV_48289723_G & TGAAAATGGGTCGGGTCGGAC \\
BCMV_48289723_A & CTTGAAAATGGGTCGGGTCGGAT & $48,289,742$ \\
CAPS marker & & $48,289,744$ \\
BCMV_48289723_CAPS & AGGAGGAAGAACGGTGGTC & $48,289,519$ \\
& TTTGGTGGTAATTTGAAAATGG & $48,289,829$ \\
\hline
\end{tabular}


with the dominant SW13 SCAR marker, which generates a 690 bp PCR amplicon [36], using the same PCR thermocycling conditions as those for the CAPS marker, except that the extension time was at $72^{\circ} \mathrm{C}$ for $1 \mathrm{~min}$. The recombination frequency between markers (SNP ss715641188, SW13) and the $I$ gene in the RIL population was calculated by $x^{2}$ analysis.

\section{Additional files}

Additional file 1: Table S1. Graphical genotypes of lines screened in the greenhouse and all BeanCAP accessions determined by SNPs flanking the / gene.

Additional file 2: Table S2. Graphical genotypes of RILs, derived from the cross of G122 × Montcalm, determined by SNPs flanking the I gene.

\section{Competing interests}

The authors declare that they have no competing interests.

\section{Authors' contributions}

PNM conceived, designed, oversaw the study, and assisted in manuscript preparation. MHB conducted the major part of the research, including disease resistance screening, bioinformatics analysis, genotyping, and wrote the manuscript. SMM and PEM performed genotyping and SNP calling from BARCBEAN_3 6K SNP BeadChip. MM designed and validated primers for KASP markers, and performed KASP genotyping assays. PBC designed and performed high-throughput genotyping with BARCBEAN_3 6K SNP BeadChip assay. All authors read and approved the final manuscript.

\section{Acknowledgements}

This project was funded by the Norman Borlaug Commemorative Research Initiative between USAID Feed the Future program and the USDA Agricultural Research Service. We thank Dr. Kenneth Grafton (NDSU) for providing the RIL population. MHB was partially supported by a postdoctoral fellowship from the National Council for Research and Technology (CONACYT) of Mexico.

\section{Author details}

'Vegetable and Forage Crops Research Unit, USDA, Agricultural Research Service, Prosser, WA 99350, USA. ${ }^{2}$ Department of Plant Sciences and Genomics and Bioinformatics Program, North Dakota State University, Fargo, ND 58108, USA. ${ }^{3}$ Ag-Biotech Inc., 2191 San Juan Hollister Rd., San Juan Bautista, CA 95045, USA. ${ }^{4}$ Soybean Genomics and Improvement Laboratory, USDA, Agricultural Research Service, Beltsville, MD 20705, USA.

Received: 28 June 2014 Accepted: 6 October 2014 Published: 16 October 2014

\section{References}

1. Collard BCY, Mackill DJ: Marker-assisted selection: an approach for precision plant breeding in the twenty-first century. Philos Trans $R \operatorname{Soc} B$ 2008, 363:557-572.

2. Bernardo R: Molecular markers and selection for complex traits in plants: learning from the last 20 years. Crop Sci 2008, 48:1649-1664.

3. $\mathrm{XU}$ Y, Crouch JH: Marker-assisted selection in plant breeding: from publications to practice. Crop Sci 2008, 48:391-407.

4. Gepts P, Aragao FJL, de Barros E, Blair MW, Brondani R, Broughton W, Galasso I, Hernández G, Kami J, Lariquet P, McClean P, Melotto M, Miklas P. Pauls P, Pedrosa-Harand A, Porch T, Sánchez F, Sparvoli F, Yu K: Genomics of phaseolus beans, a major source of dietary protein and micronutrients in the tropics. In Genomics of Tropical Crop Plants. Edited by Moore PH, Ming R. New York, USA: Springer; 2008:113-143.

5. Kelly JD, Gepts P, Miklas PN, Coyne DP: Tagging and mapping of genes and QTL and molecular marker-assisted selection for traits of economic importance in bean and cowpea. Field Crop Res 2003, 82:135-154.
6. Miklas PN, Kelly JD, Beebe SE, Blair MW: Common bean breeding for resistance against biotic and abiotic stresses: from classical to MAS breeding. Euphytica 2006, 147:105-131.

7. Mukeshimana G, Paneda A, Rodriguez-Suarez C, Ferreira JJ, Ramon G, Kelly JD: Marker linked to the $b c 3$ gene conditioning resistance to bean common mosaic potyviruses in common bean. Euphytica 2005, 144:291-299.

8. Haley SD, Afanador L, Kelly JD: Identification and application of a random amplified polymorphic DNA marker for the I gene (povyvirus resistance) in common bean. Phytopath 1994, 84:157-160.

9. Miklas PN, Fourie D, Wagner J, Larsen RC, Mienie CMS: Tagging and mapping Pse-1 gene for resistance to halo blight in common bean differential cultivar UI3. Crop Sci 2009, 49:41-48.

10. Michelmore RW, Paran I, Kesseli RV: Identification of markers linked to disease resistance genes by bulked segregant analysis: a rapid method to detect markers in specific genomic regions using segregating populations. Proc Natl Acad Sci U S A 1991, 88:9828-9832.

11. Miklas PN, Stavely JR, Kelly JD: Identification and potential use of a molecular marker for rust resistance in common bean. Theor Appl Genet 1993, 85:745-749.

12. Miklas PN, Johnson E, Stone V, Beaver JS, Montoya C, Zapata M: Selective mapping of QTL conditioning disease resistance in common bean. Crop Sci 1996, 36:1344-1351.

13. Gepts P: Development of an integrated linkage map. In Development in Plant Breeding, Common Bean Improvement in the Twenty-First Century. Edited by Singh SP. Dordrecht, The Netherlands: Kluwer Academic Publishes; 1999:53-91.

14. Larsen RC, Miklas PN: Generation and molecular mapping of a sequence characterized amplified region marker linked with the Bct gene for resistance to Beet curly top virus in common bean. Phytopathology 2004, 94:320-325.

15. Vandemark G, Miklas PN: Genotyping common bean for the potyvirus resistance alleles $I$ and $b c-1^{2}$ with a multiplex real-time polymerase chain reaction assay. Phytopath 2005, 95:499-505.

16. Miklas PN, Coyne DP, Grafton KF, Mutlu N, Reiser J, Lindgren DT, Singh SP: A major QTL for common bacterial blight resistance derives from the common bean great northern landrace cultivar Montana No. 5. Euphytica 2003, 131:137-146

17. Bolger ME, Weisshaar B, Scholz U, Stein N, Usadel B, Mayer FX: Plant genome sequencing - applications for crop improvement. Curr Opin Biotechnol 2014, 26:31-37.

18. Perez-de-Castro AM, Vilanova S, Canizares J, Pascual L, Blanca JM, Diez MJ, Prohens J, Pico B: Application of genomic tools in plant breeding. Curr Genomics 2012, 13:179-195.

19. Henry R, Edwards M, Waters DLE, Krishnan G, Bundock P, Sexton TR, Masouleh A, Nock C, Pattemore J: Application of large-scale sequencing to marker discovery in plants. J Biosci 2012, 37:829-841.

20. Mammadov J, Aggarwal R, Buyyarapu R, Kumpatla S: SNP markers and their impact on plant breeding. Int J Plant Genomics 2012, doi: 10.1155/ 2012/728398.

21. Hyten DL, Song QJ, Fickus EW, Quigley CV, Lim IY, Choi JS, Hwang EY, Pastor-Corrales M, Cregan PB: High-throughput SNP discovery and assay development in common bean. BMC Genomics 2010, 11:475.

22. Moghaddam SM, Song Q, Mamidi S, Schmutz J, Lee R, Cregan P, Osorno JM, McClean PE: Developing market class specific InDel markers from next generation sequence data in Phaseolus vulgaris L. Front Plant Sci 2014, 5:185.

23. Schmutz J, McClean PE, Mamidi S, Wu GA, Cannon SB, Grimwood J, Jenkins J, Shu S, Song Q, Chavarro C, Torres-Torres M, Geffroy V, Moghaddam SM, Gao D, Abernathy B, Barry K, Blair M, Brick MA, Chovatia M, Gepts P, Goodstein DM, Gonzales M, Hellsten U, Hyten DL, Jia G, Kelly JD, Kudrna D, Lee R, Richard MMS, Miklas PN, et al: A reference genome for common bean and genome-wide analysis of dual domestications. Nat Genet 2014, 46:707-713. doi:10.1038/ng.3008.

24. Pfender WF, Saha MC, Johnson EA, Slabaugh MB: Mapping with RAD (restriction-site associated DNA) markers to rapidly identify QTL for stem rust resistance in Lolium perenne. Theor Appl Genet 2011, 122:1467-1480.

25. Takagi H, Abe A, Yoshida K, Kosugi S, Natsume S, Mitsuoka C, Uemura A, Utsushi H, Tamiru M, Takuno S, Innan H, Cano LM, Kamoun S, Terauchi R: QTL-seq: Rapid mapping of quantitative trait loci by whole genome resequencing of DNA from two bulked populations. Plant J 2013, 74:174-183. 
26. Yang $\mathrm{H}$, Tao Y, Zheng Z, Li C, Sweetinham MW, Howieson JG: Application of next-generation sequencing for rapid marker development in molecular plant breeding: a case study on anthracnose disease resistance in Lupinus angustifolius L. BMC Genomics 2012, 13:318,

27. Yang H, Tao Y, Zheng Z, Shao D, Li A, Sweetingham MW, Buirchell BJ, Li C: Rapid development of molecular markers by next-generation sequencing linked to a gene conferring phomopsis stem blight disease resistance for marker-assisted selection in lupin (Lupinus angustifolius L.) breeding. Theor Appl Genet 2013, 126:511-522.

28. Hu Z, Hua W, Huang S, Yang H, Zhan G, Wang X, Liu G, Wang H: Discovery of pod shatter-resistant associated SNPs by deep sequencing of a representative library followed by bulk segregant analysis in rapeseed. PLoS One 2012, 7:e34253.

29. Liu S, Yeh CT, Tang HM, Nettleton D, Schnable PS: Gene mapping via bulked segregant RNA-Seq (BSR-Seq). PLoS One 2012, 7:e36406.

30. Trick M, Admski NM, Mugford SG, Jiang CC, Febrer M, Uauy C: Combining SNP discovery from next-generation sequencing data with bulked segregant analysis (BSA) to fine-map genes in polyploidy wheat. BMC Plant Biol 2012, 12:14.

31. Viteri D, Cregan P, Trapp J, Miklas P, Shree S: A new common bacterial blight resistance QTL in VAX 1 common bean and interaction of the new QTL, SAP6, and SU91 with bacterial strains. Crop Sci 2014, 54:1598-1608

32. Miklas PN, Fourie D, Trapp J, Davis J, Myers JR: New loci including Pse-6 conferring resistance to halo blight on chromosome Pv04 in common bean. Crop Sci 2014, 54:2099-2108.

33. Mukeshimana G, Butare L, Cregan PB, Blair MW, Kelly JD: Quantitative trait loci associated with drought tolerance in common bean. Crop Sci 2014, 54:923-938.

34. Drijfhout E: Genetic Interaction Between Phaseolus Vulgaris and Bean Common Mosaic Virus Resistance With Implications for Strain Identification and Breeding for Resistance. Wageningen, The Netherlands: Centre Agric. Publ. Doc; 1978.

35. Vallejos CE, Astua-Monge G, Jones V, Plyler TR, Sakiyama NS, Mackenzie SA: Genetic and molecular characterization of the I locus of Phaseolus vulgaris. Genetics 2006, 172:1229-1242.

36. Melotto M, Afanador L, Kelly JD: Development of a SCAR marker linked to the / gene in common bean. Genome 1996, 39:1216-1219.

37. Ariyarathne HM, Coyne DP, Jung G, Skroch PW, Vidaver AK, Seadman JR, Miklas PN: Molecular mapping of disease resistance genes for halo blight, common bacterial blight, and bean common mosaic virus in a segregation population of common bean. J Am Soc Hortic Sci 1999, 124:654-662.

38. Kelly JD, Afanador L, Haley SD: Pyramiding genes for resistance to bean common mosaic virus. Euphytica 1995, 82:207-212.

39. Miklas PN, Deidré F, Trapp J, Larsen RC, Chavarro C, Blair MW, Gepts P: Genetic characterization and molecular mapping Pse-2 gene for resistance to halo blight in common bean. Crop Sci 2011, 51:2439-2448.

40. Kelly JD: A review of varietal response to bean common potyvirus in Phaseolus vulgaris. Plant Varieties Seeds 1997, 10:1-6.

doi:10.1186/1471-2164-15-903

Cite this article as: Bello et al: Application of in silico bulked segregant analysis for rapid development of markers linked to Bean common mosaic virus resistance in common bean. BMC Genomics 2014 15:903.

\section{Submit your next manuscript to BioMed Central and take full advantage of:}

- Convenient online submission

- Thorough peer review

- No space constraints or color figure charges

- Immediate publication on acceptance

- Inclusion in PubMed, CAS, Scopus and Google Scholar

- Research which is freely available for redistribution

Submit your manuscript at www.biomedcentral.com/submit
Ciomed Central 